\title{
Constructivism, Intersubjectivity, Provability, and Triviality ${ }^{*}$ Andrea Guardo
}

Sharon Street (2008, p. 223) defines constructivism about practical reasons as the view that:

[...] the fact that $X$ is a reason to $Y$ for agent $A$ is constituted by the fact that the judgment that $X$ is a reason to $Y$ (for $A$ ) withstands scrutiny from the standpoint of $A$ 's other judgments about reasons. ${ }^{1}$

This is, of course, a subjectivist view, since it has that whether $X$ is a reason to $Y$ for $A$ depends on $A$ 's normative point of view (see, e.g., Street 2008, p. 219), on what $A$ - as a matter of fact - values. ${ }^{2}$ However, different brands of constructivism are subjectivist to different degrees (see, e.g., Street 2016, § 2 and 2008, pp. 243-244). According to Korsgaard's (e.g. 1996) Kantian constructivism, for instance, even though the truth value of a judgment about practical reasons always depends on the agent's normative point of view, there are certain - moral - judgments which are true relative to every possible normative point of view; this is not objectivity, but it is at least a very strong form of intersubjectivity. On the other hand, Humean constructivists - such as Bernard Williams (e.g. 1979) and Street herself - maintain that an unrestricted intersubjectivity is no more attainable than real objectivity. An ideally coherent Caligula, who has conclusive reasons to torture others for fun, is entirely possible (see esp. Street $2009 \mathrm{~b}$ and 2012, §§ 3-6). In Street's (2010, p. 370) own words:

According to Humean constructivists, similarities in human beings' reasons [...] ultimately depend for their existence on contingent similarities in people's evaluative starting points and circumstances - on the existence of a shared human nature $[\ldots]$.

Street's version of Humean constructivism, however, comes with an important qualification, since Street $(2016, \S 12)$ has maintained that, in fact, there is one conclusion about practical reasons which is entailed from within every possible

\footnotetext{
* I would like to thank Shanna Slank, Elliott Sober, Rowland Stout, Sharon Street, and Mike Titelbaum for comments on previous versions of this paper.

${ }^{1}$ See also the "brief evolutionary thought experiment" of $\S 5$. Note that this kind of view bears a strong analogy to Stanley's (2005) interest-relative invariantism about knowledge in that it has that the relevant standpoint is the agent's; Street argues for this in her 2008, p. 224 - on this issue see also Prinz 2007, §§ 5.1.2-5.1.3 and Schafer 2014.

${ }^{2}$ For the attitude of valuing see Street 2012, $\S 2$.
} 
normative point of view, namely the constructivist thesis itself. Therefore, Street's Humean constructivism has, as it were, a Kantian basis. ${ }^{3}$ Or at least so Street has maintained.

In the first part of the paper (sections 1 and 2) I argue that the Kantian basis thesis is inconsistent with another tenet of Street's, namely that the constructivist thesis holds also in the domain of epistemic reasons. ${ }^{4}$ Since I find Street's case for constructivism about epistemic reasons quite convincing, I take this to be strong evidence against the notion that constructivism about practical reasons is entailed from within every possible normative point of view. This raises some interesting questions. Street uses the Kantian basis thesis to argue that realists about practical reasons can be proved wrong employing only assumptions they themselves are committed to. She also uses the thesis to answer the worry that constructivism, if true, would be trivial. What happens to these arguments if the Kantian basis thesis is, as I argue, false? This is the topic of the second part of the paper (sections 3 and 4).

The paper's main thesis is that Street's overall position is internally inconsistent. A (Humean) constructivist about epistemic reasons cannot consistently claim that there are normative truths which are entailed from within every possible normative point of view. This inconsistency can be dealt with either by abandoning constructivism about epistemic reasons or by accepting that there are no normative truths which are entailed from within every possible normative point of view. I myself favor the latter option and the second part of the paper is, in fact, a discussion of the consequences of embracing it. However, proving that this is the right way to deal with the inconsistency in question falls outside the scope of the paper, which means that what I say in the last two sections is conditional on the assumption that epistemic normativity can be made sense of along constructivist lines. Mutatis mutandis, the same holds for Street's empirical assumptions about the etiology of our normative beliefs: I think they are justified, but I will not argue for the point, and so the paper as a whole is conditional on the assumption that they can be satisfactorily defended.

\section{The Kantian Basis Thesis}

When Street says that constructivism about practical reasons is entailed from within every possible normative point of view, what she has in mind is that a certain argument for constructivism, her Darwinian Dilemma, is sound relative to

\footnotetext{
${ }^{3}$ For another sense in which Street's Humean constructivism is Kantian see her 2008, pp. 244-245.

${ }^{4}$ Note that Street $(2009 \mathrm{a}, \S 3)$ distinguishes, I think correctly, between the concept of an epistemic reason and that of a reason for belief. An epistemic reason is a reason to believe that $\mathrm{p}$ that tells in favor of the truth of $p$.
} 
every possible normative point of view (see Street 2016, § 12). Therefore, the best way to show that the Kantian basis thesis is inconsistent with constructivism about epistemic reasons is by showing that given constructivism about epistemic reasons, there are possible normative points of view relative to which the Darwinian Dilemma is unsound. This is the strategy that I will pursue in this and the next section.

Let us start with the Darwinian Dilemma. The first thing to note is that it comes in different versions, each one focusing on a different metaethical alternative, but each one trying to show - by means of different elaborations of the same evolutionary core - that a proponent of the metaethical view in question has very strong reasons to abandon it in favor of some form of constructivism. For simplicity's sake, here I will focus on the version which deals with what has come to be known as non-natural realism: ${ }^{5}$

Non-Natural Realism: there are objective irreducibly normative truths (see, e.g., Enoch 2011, pp. 3-4 and Street 2006, § 2 and 2010, § 5).

Here is (a somewhat sketchy version of) the argument. Let Shanna be a nonnatural realist about practical reasons. This means that Shanna disagrees with the constructivist about the status of practical normativity. However, Shanna and the constructivist agree in most of their first-order judgments about what people have reasons to do - they agree that the fact that the chocolate cookies I ate this morning were delicious was a reason, even though maybe not a conclusive one, for me to eat them all, and so on. What is most important, though, is that Shanna and the constructivist also agree about the following non-normative claim:

Evolutionary Theory: "[...] the forces of natural selection have had a tremendous influence on the content of human evaluative judgments" (Street 2006, p. 113). ${ }^{6}$

\footnotetext{
${ }^{5}$ For the version focusing on natural realism see Street 2006, $\S 7$, for that dealing with quasi-realism see Street 2011.

${ }^{6}$ For a nice discussion of the point see Street 2006, § 4. For a defense of the use of genealogical considerations see Street 2015, §§ 1-2. For a useful taxonomy of the ways in which natural selection may have influenced our evaluative judgments see Joyce 2006, chapter 1, but keep in mind that such taxonomical issues are controversial - see, e.g., Sober and Wilson's (1998, pp. 79-86) discussion of the relation between group selection models (for which see, e.g., Sober and Wilson 1998, chapter 1) and evolutionary game theory models (for which see, e.g., Axelrod 1984, chapter 5). For the role of cultural evolution see Boyd and Richerson 2005, part 3. Finally, it is worth stressing that the empirical assumptions of Street's argument are weaker than one might think (see Street 2006, p.
} 
The question is: what can Shanna say about the relation between these selective forces and the objective irreducibly normative truths she posits?

The first option is to deny that there is any relation:

The No-Relation View: there is no relation between the selective forces that shaped our evaluative judgments and the objective irreducibly normative truths about practical reasons.

Is this a satisfactory position? Street $(2006, \S 5)$ thinks not. Here is her first point:

The key point to see about this option is that if one takes it, then the forces of natural selection must be viewed as a purely distorting influence on our evaluative judgments, having pushed us in evaluative directions that have nothing whatsoever to do with the evaluative truth. [...] every now and then, Darwinian pressures might have happened to push us toward accepting an evaluative judgment that accords with one of the realist's independent evaluative truths. But this would be purely a matter of chance [...]. We have thus been guided by the wrong sort of influence from the very outset of our evaluative history, and so, more likely than not, most of our evaluative judgments have nothing to do with the truth (Street 2006, pp. 121-122).

That is: if you accept Non-Natural Realism, Evolutionary Theory, and the NoRelation view, then you should conclude that it is very likely that most of our evaluative judgments have nothing to do with the truth. ${ }^{7,8}$ But that - and this is Street's second point - would mean embracing quite a radical form of skepticism about our knowledge of what we have reason to do, or not to do (see Street 2006, p. 122) - an extremely unattractive position which, according to Street $(2015, \S$

155): for one, the relevant traits do not have to be directly selected - for the distinction direct-indirect selection see Okasha 2006, p. 25 and Sober 2000, p. 83, which uses "selection for" and "selection of"; for another, one can accept the notion that our normative judgments are the product of evolution without embracing the evolutionary psychology research program in the mainstream version popularized by Pinker 1997, which is controversial (see, e.g., Buller 2005).

${ }^{7}$ Street says that it is "more likely than not" that most of our evaluative judgments have nothing to do with the truth. I take the context to make clear that the intended claim is actually stronger: the probability in question is close to 1 .

${ }^{8}$ Slightly different readings of the passage are possible. All the available alternative readings, however, have Street making, at some point of her argument, a normative assumption - which is all that matters for the purposes of this paper. 
5), can be discarded out of hand. And since this skepticism is a consequence of the No-Relation View, this suggests that such a view cannot be taken too seriously.

The transition from the undeniable lack of appeal of the aforementioned skepticism to the notion that we can assume it - and, therefore, the No-Relation View which leads to it - to be false is not as smooth as Street makes it out to be. The notion that there are objective, but in a certain sense unknowable, irreducibly normative truths about practical reasons is, no doubt, at the very least a coherent one; and it is not clear why the fact that such a notion is unattractive should count as evidence that it is false. However, consistently with the nature of my goals in this paper and the general attitude toward Street's assumptions that I embraced above, in what follows I will bracket these worries.

The point I do want to stress is that - when she says that if you accept NonNatural Realism, Evolutionary Theory, and the No-Relation view, then you should conclude that it is very likely that most of our evaluative judgments have nothing to do with the truth - Street is making a claim about what a person who accepts certain assumptions should believe. For ease of reference, in what follows I will refer to this claim as "the Cliffordian Principle" (see Clifford 1877).

Let us now turn to Shanna's second option, which is to admit that there is indeed a relation between the workings of natural selection and the objective irreducibly normative truths she posits. According to Street (2006, pp. 134-135), such a move would commit Shanna to what Street calls "the Tracking Account":

[...] we may understand these evolutionary causes as having tracked the truth [...]. As Derek Parfit has put the point: it is possible that "just as cheetahs were selected for their speed [...] the particular feature for which we were selected was our ability to respond to reasons [...]" (Street 2006, pp. 125-126).

But Shanna, being a well-educated $21^{\text {st }}$ century woman, also accepts:

The Usual Criteria of Scientific Adequacy: the competition between different scientific hypotheses should be adjudicated focusing on the degree to which they instantiate the usual theoretical virtues.

This means that Shanna accepts that the Tracking Account, which puts itself forward as a scientific hypothesis, should be compared to alternative explanations focusing on features such as parsimony, clarity, and explanatory power. And here lies the problem, because it is not hard to find a hypothesis which exemplifies the 
usual theoretical virtues to a higher degree than the Tracking Account does (see Street 2006, pp. 126-134 and 2011, § 6):

According to what I will call the adaptive link account, tendencies to make certain kinds of evaluative judgments rather than others contributed to our ancestors' reproductive success not because they constituted perceptions of independent evaluative truths, but rather because they forged adaptive links between our ancestors' circumstances and their responses to those circumstances, getting them to act, feel, and believe in ways that turned out to be reproductively advantageous (Street 2006, p. 127).

Thus, Shanna has very strong reasons to abandon the Tracking Account and, with it, her realism. Indeed, since the Adaptive Link Account is perfectly consistent with constructivism (see Street 2006, pp. 152-153), Shanna has very strong reasons to abandon realism in favor of some form of constructivism.

And so, when Shanna looks at the choice between the No-Relation View and the Tracking Account reflectively, what she sees is - in fact - a choice between constructivism and an extremely unattractive form of skepticism. And this, Street thinks, gives Shanna conclusive reasons to embrace constructivism. This is the conclusion of the Darwinian Dilemma. Now the question is: is this argument really sound relative to every possible normative point of view?

\section{The Problem with the Kantian Basis Thesis}

If, as Street (2009a, §§ 6-8) argued, constructivism is the one correct view of epistemic reasons, this question must be answered in the negative. As we have seen, according to constructivism about practical reasons what reasons an agent $\mathrm{A}$ has depends on what A, as a matter of fact, values; and if A's evaluative starting point is deviant enough, A's reasons can be rather different from ours. Likewise, given constructivism about epistemic reasons, all it takes for a believer B to have (lack) reasons that normal human beings lack (have) is that B's evaluative starting point is deviant enough. In particular, if B's evaluative starting point is deviant enough, it may happen that neither the Cliffordian Principle nor the Usual Criteria of Scientific Adequacy (which are both substantive normative assumptions) are true relative to B's normative point of view. Now, let Shannon be such an idiosyncratic believer. Since it assumes both the Cliffordian Principle and the Usual Criteria of Scientific Adequacy, the Darwinian Dilemma will be unsound relative to Shannon's normative point of view, which means that the Kantian basis thesis is false.

One might try to resist this conclusion by arguing that Shannon is not a possible believer, a move which would be the epistemic parallel of Korsgaard's strategy in the domain of practical reasons. I do not find this line of argument very 
promising. Let us start with the Cliffordian Principle. This principle says that if you accept Non-Natural Realism, Evolutionary Theory, and the No-Relation view, then you should conclude that it is very likely that most of our evaluative judgments have nothing to do with the truth - for if Non-Natural Realism, Evolutionary Theory, and the No-Relation view are all true, then it is very likely that most of our evaluative judgments have nothing to do with the truth. Now, let us say that the reason why the Cliffordian Principle, which is a particular principle concerning the normative consequences of the acceptance of certain theses, is false relative to Shannon's normative point of view is that, relative to such a point of view, the fact that if $p_{1}, \ldots, p_{n}$ are all true then it is very likely that $q$ never entails that if you accept $\mathrm{p}_{1}, \ldots, \mathrm{p}_{\mathrm{n}}$ then you should conclude that it is very likely that q. Given such an assumption, one can definitely make a case that Shannon's normative point of view is not that of a real believer (see, e.g., Street 2009a, § 5). But this is not an assumption that we have to make. We could, for instance, assume that the Cliffordian Principle is false relative to Shannon's normative point of view because even though, relative to such a point of view, the fact that if $\mathrm{p}_{1}, \ldots, \mathrm{p}_{\mathrm{n}}$ are all true then it is very likely that $q$ usually entails that if you accept $\mathrm{p}_{1}, \ldots, \mathrm{p}_{\mathrm{n}}$ then you should conclude that it is very likely that q, this is not always the case; let us say, for example, that you should not conclude that it is very likely that q if drawing this conclusion would make you severely depressed - and drawing the skeptical conclusion would make Shannon severely depressed. ${ }^{9}$ Given this assumption, we can no doubt conclude that Shannon is an extremely peculiar individual, but I take it to be clear that accusing her of not being a true believer would be unwarranted.

That being said, in order for the Darwinian Dilemma to be unsound relative to Shannon's normative point of view the falsity of the Usual Criteria of Scientific Adequacy is enough. And in this case a Korsgaard-like move looks even less promising. After all, why should we think that Shannon is no believer unless she has reasons to adjudicate the competition between different scientific hypotheses focusing on the degree to which they instantiate the usual theoretical virtues? The very fact that the principle in question deals only with the assessment of scientific hypotheses strongly suggests that its truth relative to Shannon's normative point of view cannot be a necessary condition of Shannon's being a believer.

And so the Kantian basis thesis is inconsistent with constructivism about epistemic reasons. And since I find Street's argument for the latter quite solid, I think that this conclusion gives us very strong reasons to believe the Kantian basis thesis to be false. Now, if this is correct, it raises a couple of questions, one concern-

\footnotetext{
${ }^{9}$ Note how different Shannon would be from Ben and the other characters described in Street 2009a, § 6 .
} 
ing the provability of constructivism about practical reasons and another concerning the alleged triviality of this kind of position. I will address these two issues in turn.

\section{Provability}

Street thinks that one interesting feature of the Kantian basis thesis is that it shows that realists about practical reasons can be proved wrong employing only assumptions they themselves are committed to. After all, if the Kantian basis thesis were true the Darwinian Dilemma would be sound relative to every possible normative point of view, and the conclusion of the Darwinian Dilemma is that you have conclusive reasons to embrace constructivism.

However, if the Kantian basis thesis is false, as I have argued we have reasons to believe, then there are possible normative points of view relative to which the Darwinian Dilemma is unsound and its conclusion false; there are, for example, possible normative points of view whose bearers have conclusive reasons to embrace non-natural realism together with some version of the Tracking Account. These are possible realists who cannot be proved wrong employing only assumptions they themselves are committed to.

Is this a problem? It depends. As for myself, I think that if it is a problem, it is not a serious one. Even though there are possible realists who cannot be proved wrong employing only assumptions they themselves are committed to, real-life realists are very different animals. Relative to their normative point of view, the Cliffordian Principle and the Usual Criteria of Scientific Adequacy are no doubt true and the Darwinian Dilemma is therefore sound. Humean constructivism has, as it were, a quasi-Kantian basis. And as long as Street is interested in convincing real-life - rather than merely possible - realists, this is all she needs. ${ }^{10}$

\footnotetext{
${ }^{10}$ Note that the conclusion of the previous section is that there are possible normative points of view whose bearers do not have conclusive reasons to embrace constructivism. If, like Street, you take constructivism to be a judgment about practical reasons and, once again like Street, you are a constructivist about practical reasons, that conclusion entails that there are possible normative points of view relative to which constructivism is not true. However, if - say - you reject the notion that constructivism is a judgment about practical reasons, the corollary does not follow. And if you are a constructivist about practical reasons, you will conclude just that the bearers of the aforementioned possible normative points of view have no reason to believe a proposition which, as a matter of fact, is true - here it is worth keeping in mind that the possible realists in question have no reason to embrace constructivism precisely because in general their reasons depend on truth-related considerations less than ours do. And this looks like a hardly problematic conclusion.
} 


\section{Triviality}

Street has argued that the Kantian basis thesis can help us answer certain familiar worries concerning, as it were, the triviality of the constructivist position. Consider the following argument:

First premise: if constructivism about practical reasons is true the truth value of a judgment about practical reasons is always relative to a normative point of view.

Second premise: constructivism about practical reasons is itself a judgment about practical reasons.

Lemma: if constructivism about practical reasons is true it is true only relative to a normative point of view.

Conclusion: if constructivism about practical reasons is true it is trivial; realists can argue that relative to their normative point of view constructivism is false and that its truth relative to another normative point of view has no grip on them (see Street manuscript, $\S 10$ ).

If the Kantian basis thesis were true, the conclusion would not follow from the lemma, for realists could not argue that relative to their normative point of view constructivism is false. After all, if the Kantian basis thesis were true, realists themselves would have conclusive reasons to believe that constructivism is true (see Street 2016, § 12 and manuscript, § 10).

Unfortunately, the Kantian basis thesis is likely false. And so, the question is: is there any other way for constructivists to rebut the challenge of triviality? As far as I can see, here there are two strategies that a constructivist can try to develop. The first option is to rely on the fact that even though it does not have a Kantian basis, Humean constructivism has a quasi-Kantian basis. This means that even if there are possible realists who can argue that relative to their normative point of view constructivism is false, no real-life realist is like that. ${ }^{11}$ This is definitely something. That being said, I think we can do better. Here is, then, the constructivist's second option.

Let us start by noting that, of the two premises of our argument, the key one is the second, namely the claim that constructivism about practical reasons is itself a judgment about practical reasons. This is an idea I introduced, without any discussion, when I first introduced the Kantian basis thesis. It is now time to focus on it and try to make clear why Street believes it is true. The best way to do this is, I

\footnotetext{
${ }^{11}$ When I discussed the problem with Street, this was the route she was inclined to go. A couple of promissory notes (notes 25 and 27) in the most recent version I have seen of Street manuscript suggest that she still feels that way.
} 
think, to start with Street's view of the disagreement between constructivists and realists.

A somewhat plausible interpretation of the debate is that their disagreement concerns the logical form of the propositions expressed by reasons ascriptions. In other words, the point would be that, say, while the realist takes an utterance like "The fact that you need help is a reason for me to help you" at face value, the constructivist believes that the proposition expressed by this reasons ascription is really something like The fact that you need help is a reason for me to help you relative to my normative point of view. Street (manuscript, § 7) thinks that this way to view the debate is misguided and that the disagreement between constructivists and realists is really one about the way the propositions in question should be evaluated. $^{12,13}$ The realist and the constructivist can agree that, say, an utterance of "The fact that you need help is a reason for me to help you" expresses the proposition The fact that you need help is a reason for me to help you; their disagreement lies in the fact that, unlike the realist, the constructivist believes that in order to assign a truth value to this proposition we must specify what is the relevant normative point of view - in Kaplan's (1989) terminology, they agree about the content but they disagree about the form of the relevant circumstances of evaluation.

Following MacFarlane (2014, p. 62) I will call this kind of disagreement a "postsemantic" disagreement. Now, if the disagreement between constructivists and realists is a postsemantic one, constructivism has to be a postsemantic thesis, a thesis about the way certain propositions should be evaluated. Why then does Street think that constructivism is a judgment about practical reasons? As far as I can see, she has two different sets of reasons (see Street manuscript, § 8). First, the truth of constructivism (the postsemantic thesis that in order to assign a truth value to a proposition about practical reasons we must specify the relevant normative point of view) entails that of:

The C-Thesis: there are no absolute reasons, only relative ones.

\footnotetext{
${ }^{12}$ Her terminology is different from mine: she says that the concept of a normative reason is neutral on the debate between realism and constructivism. I take this to be only a terminological difference.

${ }^{13}$ Note that Street also agrees with a realist like Scanlon (see, e.g., 2014) that reasons are just facts: it was the fact that the chocolate cookies I ate this morning were delicious which was a reason for me to eat them all. The disagreement between constructivists and realists, therefore, is not one concerning what kind of things reasons are either, at least in Street's view.
} 
And the C-Thesis seems to deserve to be called "a judgment about practical reasons". Second, the truth of constructivism affects the truth value of propositions which are clearly judgments about practical reasons. For example, if (Humean) constructivism is true, then it is true also that an ideally coherent Caligula has conclusive reasons to torture others for fun.

Is this enough to say that constructivism is a judgment about practical reasons and make our argument sound? I think not. As for the first point, I agree that if the C-Thesis really deserved to be called "a judgment about practical reasons", constructivism would be a judgment about practical reasons, too. After all, constructivism and the C-Thesis say basically the same thing. The only difference is that while the first focuses on propositions, the second focuses on the corresponding facts. The problem is that the C-Thesis is not really a judgment about practical reasons, or better: it is not a judgment about practical reasons in the sense relevant to the argument we are discussing. The relevant sense is that at issue in the first premise - if "judgment about practical reasons" were not used in the same sense throughout it, the argument would be invalid. And in that premise a judgment about practical reasons is a judgment about the reasons a given agent has, a judgment about what that agent should do - the judgments about practical reasons mentioned there are the judgments object of constructivism about practical reasons, and the object of constructivism about practical reasons are judgments about the reasons a given agent has. And this is just not the logical form of the C-Thesis.

What about the second point? Judgments like that an ideally coherent Caligula has conclusive reasons to torture others for fun are, of course, judgments about practical reasons in the relevant sense. But this, even taken together with the fact that the truth of constructivism affects the truth value of these propositions, does not mean that constructivism is a judgment about practical reasons - in the relevant sense. Countless propositions which are not judgments about practical reasons affect the truth value of judgments about practical reasons. I take it to be clear, for instance, that had I not liked chocolate I would not have had any reason to eat all those cookies this morning.

I therefore think that if Street does not have other reasons to believe that constructivism is a judgment about what people should do (in the relevant sense), she should just regard our argument's second premise as false and the argument itself as unsound. ${ }^{14}$ This seems to me to be the best answer to the triviality objection. ${ }^{15}$

\footnotetext{
${ }^{14}$ At one point, Street (manuscript, p. 15) comes close to rejecting the premise in question: she says that the constructivist thesis does not, taken by itself, apply to itself. However, she then goes on to say that she regards the constructivist thesis as itself a substantive normative claim about what reasons there are and that this entails that constructivism is true only relative to a normative point of view. I am not sure this is a consistent position: if by "a substantive normative claim about what reasons there are" Street means $a$
} 
International Journal of Philosophical Studies, forthcoming

judgment about what certain agents should do, then constructivism applies to itself; if not, I do not understand why constructivism should be thought to be true only relative to a normative point of view. That being said, it seems clear that Street does accept our argument's second premise.

${ }^{15}$ Note that the fact that our argument's second premise is false gives us another route to the conclusion that the Kantian basis thesis is false: even if the Darwinian Dilemma were really sound relative to every possible normative point of view, the Kantian basis thesis would be false because constructivism is not a judgment about what people should do. 


\section{References}

Axelrod, Robert (1984). The Evolution of Cooperation. New York: Basic Books. Boyd, Robert; Richerson, Peter J. (2005). The Origin and Evolution of Cultures. New York-Oxford: Oxford University Press.

Buller, David J. (2005). Adapting Minds - Evolutionary Psychology and the Persistent Quest for Human Nature. Cambridge-London: MIT Press.

Clifford, William Kingdon (1877). The Ethics of Belief. Contemporary Review 29 (1), 289-309.

Enoch, David (2011). Taking Morality Seriously - A Defense of Robust Realism. New York-Oxford: Oxford University Press.

Joyce, Richard (2006). The Evolution of Morality. Cambridge-London: MIT Press.

Kaplan, David (1989). Demonstratives - An Essay on the Semantics, Logic, Metaphysics, and Epistemology of Demonstratives and Other Indexicals. In Joseph Almog, John Perry, Howard Wettstein (eds.), Themes from Kaplan. New YorkOxford: Oxford University Press, 481-563.

Korsgaard, Christine M. (1996). The Sources of Normativity. Cambridge: Cambridge University Press.

MacFarlane, John (2014). Assessment Sensitivity - Relative Truth and Its Applications. New York-Oxford: Oxford University Press.

Okasha, Samir (2006). Evolution and the Levels of Selection. New York-Oxford: Oxford University Press.

Pinker, Steven (1997). How the Mind Works. London: Penguin Books.

Prinz, Jesse J. (2007). The Emotional Construction of Morals. New York-Oxford: Oxford University Press.

Scanlon, T. M. (2014). Being Realistic about Reasons. New York-Oxford: Oxford University Press.

Schafer, Karl (2014). Constructivism and Three Forms of PerspectiveDependence in Metaethics. Philosophy and Phenomenological Research 89 (1), 68-101.

Sober, Elliott (2000). Philosophy of Biology. Boulder: Westview Press.

Sober, Elliott; Wilson, David Sloan (1998). Unto Others - The Evolution and Psychology of Unselfish Behavior. Cambridge-London: Harvard University Press. Stanley, Jason (2005). Knowledge and Practical Interests. New York-Oxford: Oxford University Press.

Street, Sharon (2006). A Darwinian Dilemma for Realist Theories of Value. Philosophical Studies 127 (1), 109-166.

Street, Sharon (2008). Constructivism about Reasons. Oxford Studies in Metaethics 3 (1), 207-245. 
Street, Sharon (2009a). Evolution and the Normativity of Epistemic Reasons. $\mathrm{Ca}$ nadian Journal of Philosophy 39 (supplement), 213-248.

Street, Sharon (2009b). In Defense of Future Tuesday Indifference: Ideally Coherent Eccentrics and the Contingency of What Matters. Philosophical Issues 19 (1), 273-298.

Street, Sharon (2010). What Is Constructivism in Ethics and Metaethics?. Philosophy Compass 5 (5), 363-384.

Street, Sharon (2011). Mind-Independence without the Mystery: why QuasiRealists Can't Have It Both Ways. Oxford Studies in Metaethics 6 (1), 1-32.

Street, Sharon (2012). Coming to Terms with Contingency: Humean Constructivism about Practical Reason. In James Lenman, Yonatan Shemmer (eds.), Constructivism in Practical Philosophy. New York-Oxford: Oxford University Press, 40-59.

Street, Sharon (2015). Does Anything Really Matter or Did We Just Evolve to Think So?. In Alex Byrne, Joshua Cohen, Gideon Rosen, Seana Shiffrin (eds.), The Norton Introduction to Philosophy. New York: Norton, 685-693.

Street, Sharon (2016). Objectivity and Truth: You'd Better Rethink It. Oxford Studies in Metaethics 11 (1), 293-334.

Street, Sharon (manuscript). How to Be a Relativist about Normativity. Williams, Bernard (1979) [1981]. Internal and External Reasons. In Bernard Williams, Moral Luck - Philosophical Papers 1973-1980. Cambridge: Cambridge University Press, 101-113. 